\title{
HUBUNGAN FAKTOR PERSONAL DAN PENGAWASAN KERJA DENGAN TINDAKAN TIDAK AMAN PADA PEKERJA PENGELASAN DI BENGKEL LAS ABUN DESA SKIP KECAMATAN LUBUK PAKAM KABUPATEN DELI SERDANG
}

\author{
Rosita Ginting ${ }^{1}$, Irmayani ${ }^{2}$, Anggi Isnani Parinduri ${ }^{3}$, \\ Muhammad Dani Harahap ${ }^{4}$ \\ Progaran Studi Kesehatan Masyarakat Fakultas Kesehatan Masyarakat \\ Institut Kesehatan Medistra Lubuk Pakam \\ Jl. Sudirman No.38 Lubuk Pakam Kec. Lubuk Pakam Kab. Deli Serdang, \\ Sumatera Utara \\ Email: rositaginting25@gmail.com \\ DOI :
}

\begin{abstract}
Work accidents are unwanted and unexpected events. Based on the Loss Caution Model theory, the direct causes of accidents are unsafe action and unsafe conditions. The purpose of this study was to analyze the relationship between personal factors and work supervision and unsafe action in welding workers at the Abun Las Workshop. This research type is quantitative with cross sectional research design. The population in this study were all welding workers, amounting to 34 people. The sampling technique was using the total sampling technique. The research instruments used in this study were questionnaires and observation sheets. The data obtained were processed by using the chi square statistical test with the degree of significance $(a)=0.05$. The results of the analysis of the relationship between personal factors and work supervision with unsafe action on welding workers at the Las Abun Workshop are described as follows: personal factors ( $p$ value $=0.002)<a(0.05)$, this means that there is a significant relationship between personal factors (knowledge) and unsafe action on welding workers at the Las Abun Workshop, work supervision ( $p$ value $=0.038)<a(0.05)$, this means that there is a significant relationship between work supervision and unsafe action on welding workers at the Las Abun Workshop. Suggestions for the Abun Welding Workshop industry It is better if
\end{abstract}


Jurnal Kesehatan Masyarakat \& Gizi, e-ISSN: 2655-0849

Vol. 3 No.1 Edisi Mei-Oktober 2020

https://ejournal.medistra.ac.id/index.php/JKG

ins:/ejournalmedistra.acid/index.php/JkG

Received: 10 Oktober 2020 :: Accepted: 14 Oktober 2020 :: Published: 31 Oktober 2020

the Welding Workshop Industry has Occupational Safety and Health (K3) experts who can control and supervise all activities of welding workers at any time.

Keywords: Personal factors, Unsafe Action, work supervision, welding workers 


\section{Pendahuluan}

Kecelakaan industri yaitu kecelakaan yang terjadi di tempat kerja terkhusus di lingkungan industri. Kecelakaan industri secara umum dibagi menjadi 2 bagian diantaranya tindakan tidak aman dan kondisi tidak aman. Hasil penelitian menyebutkan faktor manusia beperan penting terhadap kejadian kecelakaan kerja. Hasil penelitian menunjukkan $80 \%$ $85 \%$ kecelakaan kerja penyebabnya adalah kelalaian manusia (Maeka, 2016).

Setiap tahun sekitar 380.000 pekerja atau $13,7 \%$ dari 2,78 juta pekerja tewas karena kecelakaan kerja, salah satu penyebabnya masih rendahnya kesadaran pengusahan dan karyawan akan pentingnya penerapan K3 (International Labour Organzation, 2018). Kasus kecelakaan kerja menunjukkan peningkatan setaip tahunnya, tercatat dari data Badan Penyelenggara Jaminan Sosial (BPJS) pada tahun 2017, angka kecelakaan kerja mencapai 123.041 kasus dan tahun 2018 tercatat angka kecelakaan kerja sebanyak 173.105 kasus (Depkes RI, 2018).

Faktor personal berperan sebagai penentu interaksi sosial dalam membentuk perilaku individu. Faktor Personal menjadi salah satu sebab atau faktor yang mendasari terjadinya kecelakaan kerja yang berasal dari manusia atau para pekerjanya sendiri.
Faktor Personal pada penelitian ini terkait dengan tingkat pengetahuan kecelakaan dan kesehatan kerja pada pekerja pengelasan (Yudhawan dan Dwiyanti, 2016).

Pengawasan pada dasarnya merupakan suatu aktivitas kerja guna menilai seluruh kegiatan yang dilakukan telah berjalan sesuai dengan rencana atau tidak, dalam hal itu segala penyimpangan yang akan terjadi dapat segera dihindari sedini mungkin, dengan melakukan pengamatan pada setiap perbuatan baik telah selesai di kerjakan maupun yang sedang atau akan dilaksanakan (Rusdi, 2010). Pengawasan kerja yang ada di Bengkel Las Abun Desa Sekip Kecamatan Lubuk Pakam Kabupaten Deli Serdang diawasi oleh kepala tukang atau mandor yang berada dilapangan.

Tindakan tidak aman merupakan kegagalan untuk mengikuti persyaratan dan prosedur-prosedur kerja yang benar yang dapat menyebabkan terjadinya kecelakaan kerja, yaitu tindakan tanpa kualifikasi danotoritas, kurang maupun tidak menggunakan perlengkapan perlindungan diri, kegagalan dalam menyelamatkan peralatan, bekerja dengan kecepatan yang berbahaya, dan lain sebagainya (Maeka, 2016).

Berdasarkan hasil wawancara awal dengan 4 pekerja pengelasan ada beberapa resiko yang dapat terjadi diantaranya adalah cidera terkena alat 
potong, cidera tertimpah material besi, cidera terjepit besi, cidera mata karena serbuk besi hasil pemotongan, cidera terkena percikan pengelasan, cidera kepala karena terjatuh dan terbentur, cidera terkena peralatan untuk maintenance. Selain itu, hasil wawancara dengan kepala tukang atau mandor banyak pekerja berperilaku tidak aman. Perilaku tidak aman tersebut yaitu tidak menggunakan Alat Pelindung Diri (APD) sesuai dengan ketentuan, tidak mengembalikan dan merapikan peralatan setelah bekerja, merokok ditempat kerja, bercanda berlebihan ditempat kerja, dan menggunakan peralatan yang tidak aman untuk bekerja. Berdasarkan data dan hadil survei belum ada yang melakukan penelitian tentang hubungan faktor personal dan pengawasan kerja dengan tindakan tidak aman (unsafe action) pada pekerja pengelasan di Bengkel Las Abun.

\section{METODE PENELITIAN}

Jenis penelitian pada penelitian ini yaitu penelitian kuantitatif dengan pendekatan survey analitik, menggunakan desain penelitian yaitu cross sectional yang bertujuan untuk mengetahui hubungan faktor personal dan pengawasan kerja dengan tindakan tidak aman (unsafe action) pada pekerja pengelasan di Bengkel Las Abun yang diukur dikumpulkan secara bersamaan (Sugiyono, 2017). Seluruh pekerja di Bengkel Las Abun yang berjumlah 34 orang dijadikan populasi dalam penelitian dengan menggunakan teknik total sampling. Wawancara kepada responden dengan berpedoman pada kuesioner yang telah dipersiapkan dan menggunakan lembar observasi merupakan teknik yang digunakan dalam mengumpulkan data primer. Sedangkan data sekunder diperoleh dari Bengkel Las Abun yaitu data terkait jumlah pekerja di bengkel tersebut. Data diuji dengan chi square test pada taraf nyata 5\%. Dasar pengambilan keputusan dengan ketentuan jika nilai $\mathrm{p}<\mathrm{a}$ maka Ho ditolak yang dapat disimpulkan bahwa terdapat hubungan antara variabel independent dengan dependent.

\section{HASIL}

Tabel 1. Distribusi Responden

Berdasarkan Karakteristik di Bengkel Las Abun.

\begin{tabular}{|c|c|c|}
\hline Karakteristik & $\mathbf{n}$ & $\%$ \\
\hline \multicolumn{3}{|l|}{ Umur } \\
\hline$\geq 30$ Tahun & 20 & 58,8 \\
\hline$<30$ Tahun & 14 & 41,2 \\
\hline Total & 34 & 100,0 \\
\hline \multicolumn{3}{|l|}{ Pendidikan } \\
\hline SD & 5 & 14,7 \\
\hline SMP & 11 & 32,4 \\
\hline SMA & 17 & 50,0 \\
\hline DIII/S1 & 1 & 2,9 \\
\hline Total & 34 & 100,0 \\
\hline
\end{tabular}


Tabel 1 menunjukkan bahwa berdasarkan karakteristik diketahui mayoritas umur responden $\geq 30$ Tahun yaitu sebanyak 20 orang $(58,8 \%)$ dan mayoritas pendidikan responden yaitu SMA sebanyak 17 orang (50,0\%).

Tabel 2 Distribusi Responden

Berdasarkan Masa Kerja Pekerja Pengelasan di Bengkel Las Abun.

\begin{tabular}{ccc}
\hline Karakteristik & $\mathbf{n}$ & $\mathbf{\%}$ \\
\hline Masa Kerja & & \\
$\geq 3$ Tahun & 20 & 58,8 \\
$<3$ Tahun & 14 & 41,2 \\
\hline Total & 34 & 100,0 \\
\hline Tabel 2 & menunjukan bahwa
\end{tabular}
meyoritas masa kerja pada responden $\geq$ 3 tahun yaitu sebanyak 20 orang $(58,8 \%)$.

Tabel 3 Distribusi Responden Berdasarkan Faktor Personal Pekerja Pengelasan di Bengkel Las Abun.

\begin{tabular}{lcc}
\hline Faktor Personal & $\mathbf{n}$ & $\mathbf{\%}$ \\
\hline Tidak Baik & 22 & 64,7 \\
Baik & 12 & 35,3 \\
\hline \multicolumn{1}{c}{ Total } & $\mathbf{3 4}$ & $\mathbf{1 0 0 , 0}$ \\
\hline
\end{tabular}

Tabel 3 menunjukkan bahwa bahwa sebagian besar responden memiliki faktor personal yang tidak baik yaitu sebanyak 22 orang $(64,7 \%)$.

Tabel 4 Distribusi Responden Berdasarkan Pengawasan Kerja Pada Pekerja Pengelasan di Bengkel Las Abun.

\begin{tabular}{lcc}
\hline $\begin{array}{c}\text { Pengawasan } \\
\text { Kerja }\end{array}$ & n & \% \\
\hline Sering & 16 & 47,1 \\
\hline
\end{tabular}

\begin{tabular}{ccc}
\hline Kadang-kadang & 18 & 52,9 \\
\hline Total & 34 & 100,0 \\
\hline
\end{tabular}

Tabel 4 dapat diketahui bahwa sebagian besar pekerja menyatakan pengawasan kerja hanya kadangkadang dilakukan sebanyak 18 orang (52,9\%).

Tabel 5 Distribusi Responden

Berdasarkan Tindakan Tidak Aman

Pekerja Pengelasan di Bengkel Las Abun.

\begin{tabular}{lcc}
\hline $\begin{array}{l}\text { Tindakan Tidak } \\
\text { Aman (Unsafe } \\
\text { Action) }\end{array}$ & n & \% \\
\hline Pernah & 23 & 67,6 \\
Tidak Pernah & 11 & 32,4 \\
\hline \multicolumn{1}{c}{ Total } & 34 & 100,0 \\
\hline
\end{tabular}

Tabel 5 dapat diketahui bahwa mayoritas responden pernah melakukan tindakan tidak aman (unsafe action) sebanyak 23 orang $(67,6 \%)$.

Tabel 6 Hubungan Faktor Personal dengan Tindakan Tidak Aman (Unsafe Action) Pada Pekerja Pengelasan di Bengkel Las Abun.

\begin{tabular}{lrrrrr}
\hline \multirow{2}{*}{$\begin{array}{c}\text { Faktor } \\
\text { Personal }\end{array}$} & \multicolumn{2}{c}{$\begin{array}{c}\text { Unsafe } \\
\text { action }\end{array}$} & & Total & Nilai \\
\cline { 2 - 3 } & Tidak & Ya & & \\
\cline { 2 - 4 } & \multicolumn{1}{c}{$\mathbf{n}$} & \multicolumn{1}{c}{$\mathbf{n}$} & \multicolumn{1}{c}{$\mathbf{n}$} & \\
\hline Tidak baik & 3 & 19 & 12 & $\mathbf{0 , 0 0 2}$ \\
Baik & 8 & 4 & 12 & \\
\hline Tota & $\mathbf{1 1}$ & $\mathbf{2 3}$ & $\mathbf{3 4}$ & \\
\hline
\end{tabular}

Tabel 6 menunjukkan bahwa nilai $p(0,002)<a(0,05)$ hal ini berarti ada hubungan yang signifikan antara faktor personal dengan tindakan tidak aman 
pada pekerja pengelasan di Bengkel Las

Abun.

Tabel 7 Hubungan Pengawasan Kerja dengan Tindakan Tidak Aman Pada Pekerja Pengelasan di Bengkel Las

Abun.

\begin{tabular}{lrrrrr}
\hline \multirow{2}{*}{$\begin{array}{c}\text { Pengawas } \\
\text { an }\end{array}$} & \multicolumn{2}{c}{$\begin{array}{c}\text { Unsafe } \\
\text { action }\end{array}$} & & Total & Nilai \\
\cline { 2 - 3 } & \multicolumn{2}{c}{ Tidak } & & & \\
\cline { 2 - 3 } & $\mathbf{n}$ & $\mathbf{n}$ & $\mathbf{n}$ & \\
\hline Tidak baik & 3 & 8 & 11 & $\mathbf{0 , 0 3 8}$ \\
Baik & 8 & 15 & 13 & \\
\hline Tota & $\mathbf{1 1}$ & $\mathbf{2 3}$ & $\mathbf{3 4}$ & \\
\hline
\end{tabular}

Tabel 7 menunjukkan bahwa nilai $p(0,038)<a(0,05)$ hal ini berarti ada hubungan yang signifikan antara pengawasan kerja dengan tindakan tidak aman pada pekerja pengelasan di Bengkel Las Abun.

\section{PEMBahasan}

Sebagian besar pekerja $(64,7 \%)$ memiliki pengetahuan yang tidak baik mengenai K3. Terdapat hubungan faktor personal dengan tindakan tidak aman pada pekerja pengelasan di Bengkel Las Abun. Hal tersebut sejalan dengan penelitian yang telah dilakukan oleh Yudhawan bahwa terdapat hubungan antara faktor personal dengan tindakan tidak aman pada pekerja pengelasan di PT Dok dan Perkapalan Surabaya Tahun 2017 dengan nilai $p=0,035$ (Yudhawan dkk, 2017).

Sebagian besar responden $(52,9 \%)$ menyatakan pengawasan kerja hanya kadang-kadang dilakukan. Dalam pengawasan kerja dapat dilakukan dua teknik pengawasan agar pengawasan yang dilakukan dapat berjalan dengan baik yaitu dengan pengawasan langsung dan pengawasan tidak langsung (Yuliani, 2017). Pengawasan kerja yang ada di Bengkel Las Abun dilakukan secara langsung oleh pemilik perusahaan dan dibantu juga oleh kepala tukang yang ada di Bengkel Las Abun. Menurut Yahy, pengawasan kerja merupakan kegiatan untuk menjamin bahwa rencana yang telah dilaksanakan sesuai dengan yang telah ditetapkan (Yahya, 2016). Hasil analisis menunjukan bahwa ada hubungan antara pengawasan kerja dengan tindakan tidak aman pada pekerja pengelasan di Bengkel Las Abun Kecamatan Lubuk Pakam Kabupaten Deli Serdang Tahun 2020, dimana nilai $p(0,038)<\mathrm{a}(0,05)$.

Hal tersebut sejalan dengan hasil penelitian yang telah dilakukan oleh Sucifitriani bahwa terdapat hubungan antara pengawasan kerja dengan unsafe action pada karyawan di PT. Bukit Maradja Estate, Pematang Siantar Tahun 2015 didapatkan nilai $p=0,019$ (Sucifitriani, 2015) 


\section{KESIMPULAN}

Kesimpulan pada penelitian ini yaitu:

a. Sebagian besar pekerja pengelasan di Bengkel Las Abun memiliki faktor personal tidak baik sebanyak 22 orang $(64,7 \%)$.

b. Pengawasan kerja yang ada di Bengkel Las Abun mayoritas tidak berjalan dengan baik, 18 orang responden $(52,9 \%)$

c. Pekerja pengelasan di Bengkel Las Abun yang pernah melakukan tindakan tidak aman (unsafe action) sebanyak 23 orang $(67,6 \%)$.

d. Ada hubungan faktor personal dengan tindakan tidak aman pada pekerja pengelasan di Bengkel Las Abun Desa Sekip.

e. Ada hubungan pengawasan kerja dengan tindakan tidak aman pada pekerja pengelasan di Bengkel Las Abun Desa Sekip.

\section{DAFTAR PUSTAKA}

Depkes, RI. (2018). Kecelakaan di Industri.

http://www.depkes.go.id

International Labour Organization. (2018). Encyclopedia of Occupational Health and Safety Vol.1, Second Edition, Geneva.

Maeka, D. (2016). Pengembangan Model Hubungan Faktor Personal dan Manajemen $K 3$ terhadap Tindaan Tidak Aman (Unsafe Action) Pada Pekerja PT. Yogya
Indo Global (Tesis). FTI Institut

Teknologi Surabaya.

Rusydi. (2010). Pengaruh Pengawasan terhadap Disiplin Kerja Pegawai Kantor Departemen Agama Kabupaten Pidie. Jurnal E-Mabis FE-Uminal, Volume 11, Nomor 3, Oktober 2010.

Sucifitriani. (2015). Hubungan Pengawasan, Unsafe Action dan Unsafe Condition dengan Kecelakaan Kerja Karyawan Di Pt Bukit Maradja Estate, Pematang Siantar Tahun 2015. Diploma thesis, UPT

Sugiyono. (2017). Metode Penelitian Kuantitatif, Kualitatif dan R\&d. Bandung: Afebeta

Yudhawan, V dan Dwiyanti, E. (2017). Hubungan Personal Faktor Dengan Unsafe Action Pada Pekerja Pengelasan Di PT. Dok dan Perkapalan Surabaya. FKM Universitas Airlangga.

Yuliani, W. (2017). Pengaruh Kualitas Kerja, Pengawasan Kerja dan Kedisiplinan Kerja Terhadap Produktivitas Kerja Karyawan pada PT Pasar Raya Sri Ratu Semarang. Semarang 